\title{
The Effects of Tramadol and Levobupivacaine Infiltration on Postoperative Analgesia in Functional Endoscopic Sinus Surgery and Septorhinoplasty
}

\author{
Muhammet Hilmi Koputan, Alparslan Apan, Gökşen Öz, Emine Arzu Köse \\ Department of Anesthesiology and Reanimation, Faculty of Medicine, Kırıkkale University, Kırıkkale, Turkey
}

\section{ABSTRACT}

Objective: The aim of this prospective, randomized, double-blind study was to investigate the postoperative analgesic effects of levobupivacaine or tramadol infiltration administered prior to surgery in septorhinoplasty (SRP) or endoscopic sinus surgery (ESS).

Material and Methods: Sixty ASA class I-III adult patients electively undergoing SRP or ESC were included the study. Induction of anesthesia was performed with propofol $2-2.5 \mathrm{mg} / \mathrm{kg}$, rocuronium bromide $0.6 \mathrm{mg} / \mathrm{kg}$ and fentanyl $1 \mu \mathrm{mg} / \mathrm{kg}$ i.v. Sevoflurane $2 \%$ with an $\mathrm{N}_{2} \mathrm{O} / \mathrm{O}_{2}$ mixture (FiO $\left.: 35 \%\right)$ was used for maintenance. Tramadol $0.5 \mathrm{mg} / \mathrm{kg}$ (Group T: $n=20)$, levobupivacaine $0.25 \%(G r o u p ~ L: ~ n=20)$ and lidocaine $1 \%(G r o u p ~ C: ~ n=20)$ in a $1 / 200,000$ adrenaline solution was infiltrated into the surgical area 10 min before the operation ( $5 \mathrm{~mL}$ for ESS and $10 \mathrm{~mL}$ for SRP). All patients received fentanyl (bolus dose: $15 \mu \mathrm{g}$ and lockout interval: $10 \mathrm{~min}$ ) with a patient-controlled analgesia device during the postoperative period. Pain was assessed using an 11-point visual analogue scale (VAS) every $4 \mathrm{~h}$ for the first $24 \mathrm{~h}$. Analgesic requirements, opioid consumption and side effects in the postoperative period were recorded.

Results: There was a statistically significant decrease in postoperative fentanyl demand and consumption in patients receiving tramadol. Fentanyl doses in the $24 \mathrm{~h}$ period were $345.2 \pm 168.8 \mu \mathrm{g}, 221.1 \pm 120.6 \mu \mathrm{g}$ and $184.1 \pm 130.3 \mu \mathrm{g}(\mathrm{p}=0.002)$ for the Groups $\mathrm{C}$, L and T, respectively. There were statistically significant differences in fentanyl requirements between the tramadol and control groups at the 16, 20 and $24 \mathrm{~h}$ time points $(\mathrm{p}=0.012, \mathrm{p}=0.004$ and $p=0.002$, respectively). The side effect profiles were similar.

Conclusions: Our study indicates that the preemptive tramadol infiltration technique is an efficient, practical and safe alternative to levobupivacaine in ESS or SRP operations.

Key Words: Infiltration, levobupivacaine, tramadol, postoperative analgesia, patient-controlled analgesia

Received: 12.10.2011 Accepted: 22.03.2012

\section{Introduction}

Postoperative pain is an acute inflammatory pain that starts with surgical trauma and ends with tissue healing. It can be harmful to organ systems by initiating inflammation through different mechanisms, and the alleviation of postoperative pain is considered important for obtaining homeostasis. Pain may initiate atelectasis due to improper coughing, immobilization may cause thromboembolism and catecholamine discharge may induce cardiovascular side effects and undesired changes in neuroendocrine or metabolic function (1, 2).

Tramadol, a synthetic codeine derivative, has both opioid and non-opioid effects (3). As a commonly used drug for postoperative analgesia, tramadol decreases pain in the spinal cord with weak affinity for $\mu$ receptors, which are located in the spinal cord, by inhibiting noradrenaline and serotonin reuptake. The side effect profile is milder compared to strong opioids and it can be used by the intramuscular, intravenous or epidural routes $(4,5)$. The local anesthetic effect of tramadol has been demonstrated in minor surgical interventions and it has been effectively used for postoperative analgesia $(6,7)$. Peritonsillar tramadol infiltration has been demonstrated to decrease peri- and postoperative analgesic requirements and pain sensation (8-10).

Levobupivacaine is the " $\mathrm{s}$ " isomer of bupivacaine, a longacting amide type of local anesthetic. Cardiovascular and central nervous system toxicity induced by levobupivacaine has been demonstrated to be lower than that observed with bupivacaine in experimental animal studies, and it is well-tolerated in human volunteers $(11,12)$. In a previous study, the efficiency of levobupivacaine infiltration in postoperative analgesia was demonstrated in endoscopic sinus surgery (ESS) and septorhinoplasty (SRP) operations and was found to be superior to lidocaine (13).

The present study aimed to compare the postoperative analgesic effects of tramadol $0.5 \mathrm{mg} / \mathrm{kg}$ or levobupivacaine $0.25 \%$ infiltration to the surgical area in ESS or SRP. 


\section{Material and Methods}

The study was undertaken in accordance with the internationally accepted guidelines and the guidance issued by the Republic of Turkey Ministry of Health and published in the Official Journal dated 29 January 1993 number 21480 "Regulations Concerning Drug Research" and more recently published rules laid out in governing statutes. Following approval from the local Ethics Committee (\#2009-071), sixty American Society of Anesthesiologists (ASA) physical status I to III patients recruited for elective SRP or ESC were included in the study. Patients were informed about how to use the patientcontrolled analgesia (PCA) device and visual analogue scale during the preoperative visit.

Randomization was performed using the sealed opaque envelope technique before the operation and three equal groups were created. Patients were separately randomized according to their preoperative surgical indications until reaching the predetermined level. Patients with uncontrolled systemic disorders belonging to ASA physical status >III, a positive history of chronic pain, chronic analgesic use or analgesic requirement one day before the operation, or known allergy to one of the study medications were excluded from the study.

Patients were monitored with ECG attached at $\mathrm{V}_{5}$, noninvasive arterial blood pressure, oxygen saturation, end tidal $\mathrm{CO}_{2}$ and skin temperature (Datex-Ohmeda, Cardiocap 5 Monitor, Helsinki, Finland) and recorded every $5 \mathrm{~min}$. Venous access was achieved on the non-dominant hand with a $20 \mathrm{G}$ cannula and non-glucose containing intravenous fluid was started at a rate of $2-4 \mathrm{~mL} / \mathrm{kg} / \mathrm{h}$. Induction of anesthesia was performed using propofol $2-2.5 \mathrm{mg} / \mathrm{kg}$, rocuronium bromide $0.6 \mathrm{mg} / \mathrm{kg}$ and fentanyl $1 \mu \mathrm{g} / \mathrm{kg}$, and intubation was achieved with an appropriate enforced endotracheal tube. A sevoflurane end tidal concentration of $2-2.5 \%$ and $\mathrm{N}_{2} \mathrm{O} / \mathrm{O}_{2}$ $\left(\mathrm{FiO}_{2}: 35 \%\right)$ were adjusted for maintenance. The tidal volume was set at $8-10 \mathrm{~mL} / \mathrm{kg}$, and respiratory frequency was adjusted according to the end tidal $\mathrm{CO}_{2}$ value which was kept within 4.5-5.5 kPa (Dräger, Julian, Lubeck, Germany). The operation field was infiltrated with tramadol $0.5 \mathrm{mg} / \mathrm{kg}$, levobupivacaine $0.25 \%$ or lidocaine $1 \%$ in $1 / 200,000$ epinephrine and the final volume was substituted with saline to $5 \mathrm{~mL}$ for ESS and 10 $\mathrm{mL}$ for SRP (13). Drugs were freshly prepared before surgery in a separate room by one of the investigators (AA) who was not involved in any further observations. In the case of severe bradycardia (heart rate $<45 \mathrm{~min})$, atropine sulfate $(0.5 \mathrm{mg}$ ) was administered as a bolus, and ephedrine $5 \mathrm{mg}$ was indicated when the systolic arterial blood pressure declined by more than $20 \%$ of the baseline measurement. An atropine $15 \mu \mathrm{g} /$ $\mathrm{kg}$ and neostigmine $40 \mu \mathrm{g} / \mathrm{kg}$ mixture was administered to reverse neuromuscular block when required. Extubation was performed when respiratory effort was adequate (e.g. tidal volume $>5 \mathrm{~mL} / \mathrm{kg}$, negative inspiratory force $<25 \mathrm{mmHg}$ ).

A patient-controlled analgesia device (Provider, Abbott $\mathrm{NI}$, USA) was attached after admission to the recovery area. A bolus dose of fentanyl $15 \mu \mathrm{g}$ and a $10 \mathrm{~min}$ lockout interval was adjusted without basal infusion. Postoperative pain was assessed by a visual analogue scale (VAS) using a $10 \mathrm{~cm}$ plastic scale ranging between 0: no pain to 10: worst imaginable pain that the patient was instructed to define every 4 $\mathrm{h}$ during the first postoperative $24 \mathrm{~h}$. In the case of VAS $>4$, lornoxicam $8 \mathrm{mg}$ infusion (Xefo) was given as a rescue analgesic. Postoperative analgesic requirements and consumption were recorded. The side effect profile, including nausea, vomiting, headache, dizziness and additional analgesic use, were also recorded.

Statistical analyses were performed using the SPSS 15.0 program (SPSS Inc., Chicago, IL, USA). Our preliminary data indicated that 18 patients were required in each group to determine a $35 \%$ difference in analgesic consumption in a $24 \mathrm{~h}$ period with a power of $80 \%$. We therefore constituted each group with 20 patients to account for possible dropouts and to increase the power. Categorical data such as gender and ASA class were evaluated with the Chi-square and Fisher exact tests, and parametric values including demographic variables, hemodynamic changes and analgesic consumption were assessed with ANOVA and Bonferroni's test for post hoc comparison as appropriate. Non-parametric data such as VAS scores were compared with ANOVA and Kruskal-Wallis analysis. A p-value less than 0.05 was considered statistically significant.

\section{Results}

All patients allocated to the randomization procedure completed the study and were included in the data analysis. The demographic variables, duration and type of operation are demonstrated in Table 1. There was no significant difference in terms of age, weight, height, duration of surgery, gender, ASA physical status or type of operation.

All patients were stable in terms of hemodynamic variables such that none was required medication (data not shown). There was no significant difference in the two variables at the designated time points.

Table 1. Patient characteristics, duration and type of surgery

\begin{tabular}{|lccc|}
\hline & $\begin{array}{c}\text { Group T } \\
(\mathbf{n}=20)\end{array}$ & $\begin{array}{c}\text { Group L } \\
(\mathbf{n}=20)\end{array}$ & $\begin{array}{c}\text { Group C } \\
(\mathbf{n}=20)\end{array}$ \\
\hline Age (year) & $30.7 \pm 7.9$ & $27.2 \pm 10.3$ & $32.4 \pm 13.2$ \\
Height (cm) & $172.1 \pm 8.0$ & $173.6 \pm 7.9$ & $170.0 \pm 8.1$ \\
Weight (kg) & $76.7 \pm 13.3$ & $73.2 \pm 13.9$ & $72.5 \pm 15.0$ \\
Gender (F/M) & $7 / 13$ & $7 / 13$ & $9 / 11$ \\
ASA PS (I/II/III) & $4 / 16 / 1$ & $-/ 20 /-$ & $4 / 16 / 1$ \\
Duration of the & $92.7 \pm 31.6$ & $82.7 \pm 30.8$ & $99.0 \pm 29.4$ \\
S. (min) & & & 1 \\
ESS & 1 & 1 & 19 \\
SRP & 17 & 18 & - \\
ESS+SRP & 2 & 1 & 1 \\
\hline ASA PS: Ameican & & &
\end{tabular}

ASA PS: American Society of Anesthesiologist Physical Status, S: surgery, ESS: endoscopic sinus surgery, SRP: septorhinoplasty, values are given as number or mean \pm SD 
The VAS scores of the groups are depicted in Figure 1. While VAS at $16 \mathrm{~h}$ was significantly decreased in Group T when compared with Group C $(p=0.003)$, the difference was significant between Group L with group C at 20 h $(p=0.005)$ during the postoperative period.

Time-related PCA demands are demonstrated in Figure 2. The sum of the PCA requirements at $20 \mathrm{~h}$ was also decreased in the Group T compared to Group C $(p=0.010)$.

Analgesic consumption during the $24 \mathrm{~h}$ postoperative period are indicated in Figure 3. A significant decrease was

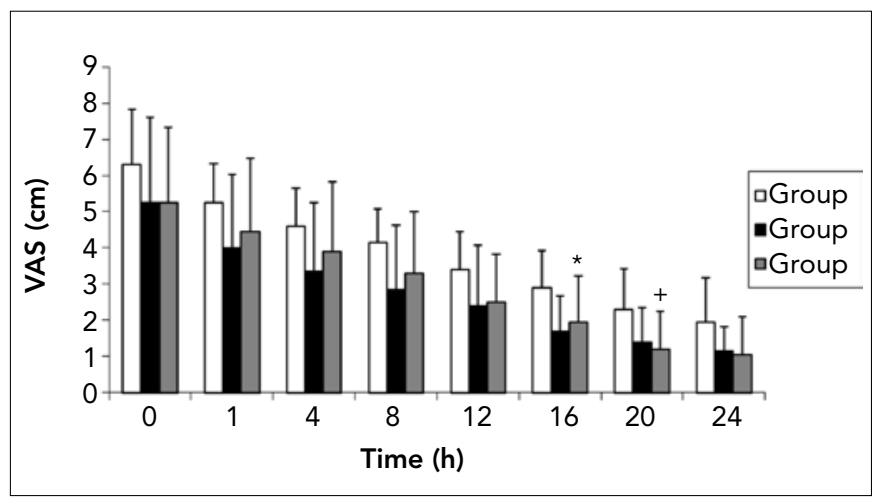

Figure 1. Changes on in the visual analogue scale (VAS) *: $p<0.05$ between Group $C$ and Group T, +: $p<0.05$ between Group $C$ and Group $L$

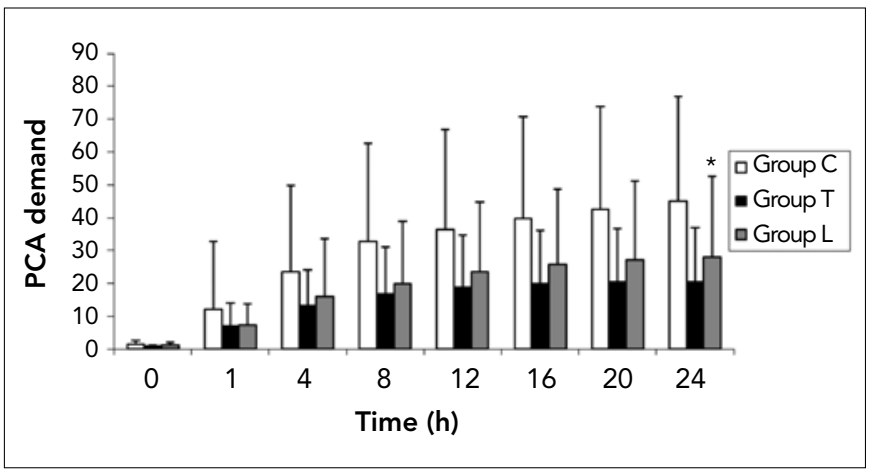

Figure 2. Demand for the patient controlled analgesia (PCA) device

*: $p<0.05$ between Group $C$ and Group $T$

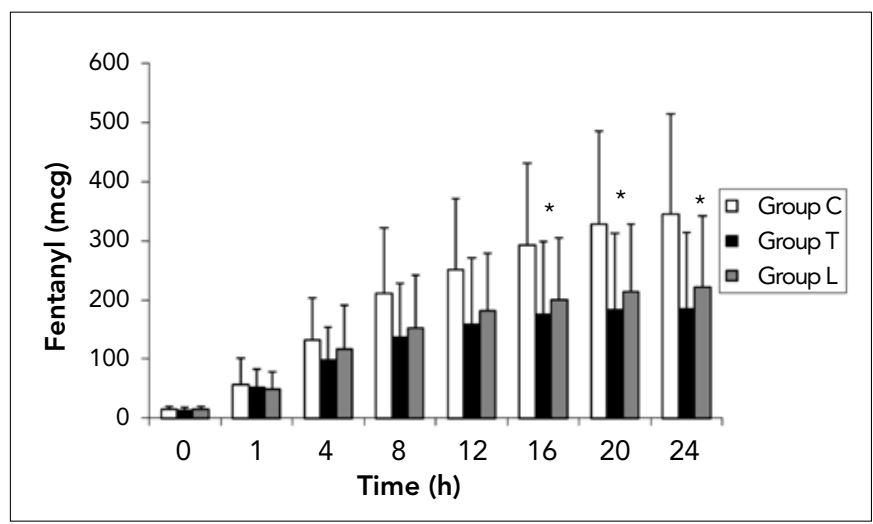

Figure 3. Fentanyl consumption in the study sroups, $\mathrm{mcg}: \mu \mathrm{g}$ *: $p<0.05$ between Group $C$ and Group $T$ observed at 16, 20 and $24 \mathrm{~h}(\mathrm{p}=0.012,0.004$ and 0.002 , respectively) in Group $T$ when compared with Group $C$. The cumulative fentanyl consumption for the postoperative $24 \mathrm{~h}$ were $345.2 \pm 168.8 \mu \mathrm{g}$ in Group C, 211.1 $\pm 120.6 \mu \mathrm{g}$ in Group $\mathrm{L}$ and $184.1 \pm 130.3 \mu \mathrm{g}$ in Group T. Three patients in Group $\mathrm{C}$ required rescue medication at postoperative $1 \mathrm{~h}$ and two patients at $4 \mathrm{~h}$. No rescue analgesic was given to the patients in the other groups.

There were no significant differences in the distribution of side effects, as indicated in Table 2.

\section{Discussion}

Our results indicate that tramadol infiltration to the operation field before nasal surgery significantly decreased analgesic requirements when compared with lidocaine, and it seemed to be as effective as levobupivacaine.

Lidocaine in an epinephrine solution is used conventionally in order to decrease perioperative bleeding and pain in the early postoperative period in ESS and SRP (14). In their study, Demiraran et al. (13) compared lidocaine with epinephrine and levobupivacaine and indicated that VAS scores together with supplemental analgesic consumption were significantly decreased in patients who received levobupivacaine infiltration. In our preliminary study, as intra-operative bleeding was not controlled adequately, it was decided to add epinephrine to all study drugs in order to eliminate the difference induced by epinephrine. We also determined the lowest effective dose of tramadol in a pilot study. Compared to Demiraran's report, the difference in analgesic consumption between the levobupivacaine and lidocaine groups did not reach significance, possibly due to the assessment of three groups and the use of epinephrine. Postoperative analgesia, which was assessed utilizing a PCA device, constitutes the other difference in methodology. It was surprising to obtain a long-lasting analgesic effect with tramadol infiltration when compared to lidocaine or levobupivacaine. In light of the usual intravenous doses (1-2 $\mathrm{mg} / \mathrm{kg}$ ) and half-life (about $5.5 \mathrm{~h}$ ) of tramadol (8), this finding could not be explained solely by its weak opioid properties; its local anesthetic and anti-inflammatory effects might also have contributed.

Surgical trauma and tampons may increase edema in the nasal mucosa and lead to inflammation. The operation field is also rich in sensitive nerves, such that pain may be more obvious due to compression induced by leaks and occlusion (15). All these features emphasize the importance of non-steroidal anti-inflammatory drug use during the postoperative period for

Table 2. Distribution of the side effect profiles

\begin{tabular}{|lccc|}
\hline & $\begin{array}{c}\text { Group T } \\
(\mathbf{n = 2 0})\end{array}$ & $\begin{array}{c}\text { Group L } \\
(\mathbf{n = 2 0})\end{array}$ & $\begin{array}{c}\text { Group C } \\
(\mathbf{n = 2 0 )}\end{array}$ \\
\hline Nausea & $8(40 \%)$ & $10(50 \%)$ & $11(55 \%)$ \\
Vomiting & $3(15 \%)$ & $4(20 \%)$ & $5(25 \%)$ \\
Dizziness & $2(10 \%)$ & $1(5 \%)$ & $1(5 \%)$ \\
Headache & $3(15 \%)$ & $3(15 \%)$ & $4(25 \%)$ \\
\hline
\end{tabular}


nasal operations $(16,17)$. On the other hand, the known side effects of anti-inflammatory medications may limit their use (1). The anti-inflammatory effects of tramadol have been demonstrated in animal studies (18). While tramadol alone decreased prostaglandin (PG) $E_{2}$, concurrent treatment with paracetamol also decreased tumor necrosis factor-alpha (TNF- $\alpha$ ) levels in the cerebrospinal fluid in a rat model of inflammatory pain (19).

Previous studies have indicated the preemptive analgesic effects of tramadol infiltration to the peritonsillar fossa at a dose of $2 \mathrm{mg} / \mathrm{kg}$, which provided an efficient but brief period of analgesia (8). On the other hand, although this method decreased pain scores in the early postoperative period, it failed to provide any advantage over the intramuscular route regarding analgesic consumption (9). Akkaya et al. (10) indicated that, when compared with intravenous administration, peritonsillar tramadol infiltration at the same dose significantly decreased analgesic requirements and side effects, including nausea and vomiting. Although the dose of tramadol for infiltration ranged between $1-2 \mathrm{mg} / \mathrm{kg}$ in these studies, we observed the efficiency of a dose of $0.5 \mathrm{mg} / \mathrm{kg}$ in our preliminary study and therefore used the minimum effective dose.

A racemic mixture of bupivacaine failed to show any advantage over lidocaine in ESS (15). However, sensorial block was found to be longer with levobupivacaine than with the racemic form $(20,21)$. The duration of the levobupivacaine infiltration significantly decreased supplemental analgesic requirements in a study including subjects undergoing both ESS and SRP (13). In our study, although a decrease in opioid consumption was detected with levobupivacaine when compared to the controls, the difference failed to reach the level of significance $(345.2 \pm 168.8 \mu \mathrm{g}$ versus $211.1 \pm 120.6 \mu \mathrm{g}$ at $24 \mathrm{~h}$ ).

In view of the present investigation, tramadol infiltration is suggested to contribute to analgesia by decreasing sensitivity in the nasal cavity, which is rich in sensitive nerves in which pain might be induced by surgical trauma (22). Besides its weak opioid and local anesthetic properties, reuptake inhibition of noradrenaline and serotonin is thought to play a role. On the other hand, the contribution of these mechanisms to the initiation of pain is unknown. In an effort to decrease side effects, the influence of lower doses remains to be determined.

\section{Conclusion}

The results of the present study suggest that tramadol infiltration might be a reasonable, practical and efficient alternative to lidocaine or levobupivacaine in ESS and SRP surgeries. Tramadol might be used in patients for whom local anesthetic use is contraindicated.

\section{Conflict of Interest}

No conflict of interest was declared by the authors.

\section{References}

1. Vadivelu N, Mitra S, Narayan D. Recent advances in postoperative pain management. Yale J Biol Med 2010;83:11-25.

2. Pyati S, Gan TJ. Perioperative pain management. CNS Drugs 2007;21:185-211. [CrossRef]
3. Ground S, Sablotzki A. Clinical pharmacology of tramadol. Clin Pharmacokinet 2004;43:879-923. [CrossRef]

4. Raffa RB, Nayak RK, Liao S, Minn FL. The mechanisms of action and pharmocokinetics of tramadol hydrochloride. Rev Contemp Pharmacother 1995;6:485-97.

5. Scott LJ, Perry CM. Tramadol: a review of its use in perioperative pain. Drugs 2000;60:139-76. [CrossRef]

6. Altunkaya H, Ozer Y, Kargi E, Babuccu O. Comparison of local anaesthetic effects of tramadol with prilocaine for minor surgical procedures. Br J Anaesth 2003;90:320-2. [CrossRef]

7. Altunkaya H, Ozer Y, Kargi E, Ozkocak I, Hosnuter M, Demirel $\mathrm{CB}$, Babuccu $\mathrm{O}$. The postoperative analgesic effects of tramadol when used as subcutaneous local anesthetic. Anesth Analg 2004;99:1461-4. [CrossRef]

8. Atef A, Fawaz AA. Peritonsillar infiltration with tramadol improves pediatric tonsillectomy pain. Eur Arch Otorhinolaryngol 2008;265:571-4. [CrossRef]

9. Ugur MB, Yilmaz M, Altunkaya H, Cinar F, Ozer Y, Beder L. Effects of intramuscular and peritonsillar injection of tramadol before tonsillectomy: a double blind, randomized, placebo-controlled clinical trial. Int J Pediatr Otorhinolaryngol 2008;72:241-8. [CrossRef]

10. Akkaya T, Bedirli N, Ceylan T, Matkap E, Gülen G, Elverici O, et al. Comparison of intravenous and peritonsillar infiltration of tramadol for postoperative pain relief in children following adenotonsillectomy. Eur J Anaesth 2009;26:333-8. [CrossRef]

11. Huang $Y$, Pryor M, Mather L, Veering B. Cardiovascular and central nervous system effects of intravenous levobupivacaine and bupivacaine in sheep. Anesth Analg 1998;86:797-804. [CrossRef]

12. Bardsley H, Gristwood R, Baker H, Watson N, Nimmo W. A comparison of the cardiovascular effects of levobupivacaine and racbupivacaine following intravenous administration to healthy volunteers. Br J Clin Pharmacol 1998;46:245-9. [CrossRef]

13. Demiraran $Y$, Ozturk O, Guclu E, Iskender A, Ergin MH, Tokmak A. Vasoconstriction and analgesic efficacy of locally infiltrated levobupivacaine for nasal surgery. Anesth Analg 2008;106:1008-11. [CrossRef]

14. Huizing EH. Functional surgery in inflammation of the nose and paranasal sinuses. Rhinol Suppl 1988;5:5-15.

15. Friedman M, Venkatesan TK, Lang D, Caldarelli DD. Bupivacaine for postoperative analgesia following endoscopic sinus surgery. Laryngoscope 1996;106:1382-5. [CrossRef]

16. Leykin Y, Casati A, Rapotec A, Dal Sasso M, Barzan L, Fanelli G, et al. A prospective, randomized, double-blind comparison between parecoxib and ketorolac for early postoperative analgesia following nasal surgery. Minerva Anestesiol 2008;74:475-9.

17. Church CA, Stewart C, O-Lee TJ, Wallace D. Rofecoxib versus hydrocodone/acetaminophen for postoperative analgesia in functional endoscopic sinus surgery. Laryngoscope 2006;116:602-6. [CrossRef]

18. Buccellati C, Sala A, Ballerio R, Bianchib M. Tramadol anti-inflammatory activity is not related to a direct inhibitory action on prostaglandin endoperoxide synthases. Eur J Pain 2000;4:413-5. [CrossRef]

19. Bianchi M, Martucci C, Ferrario P, Franchi S, Sacerdote P. Increased tumor necrosis factor- $\alpha$ and prostaglandin E2 concentrations in the cerebrospinal fluid of rats with inflammatory hyperalgesia. The effects of analgesic drugs. Anesth Analg 2007;104:949-54. [CrossRef]

20. Foster RH, Markham A. Levobupivacaine: a review of its pharmacology and use as a local anaesthetic. Drugs 2000;59:551-79. [CrossRef]

21. McLeod OA, Burke D. Review Article: Levobupivacaine. Anaesthesia 2001;56:331-41. [CrossRef]

22. Power I, Barratt S. Analgesic agents for the postoperative period: nonopioids. Surg Clin North Am 1999;79:275-95. [CrossRef] 